\title{
Mouse cloning and somatic cell reprogramming using electrofused blastomeres
}

Amjad Riaz ${ }^{1,2,{ }^{*}}$, Xiaoyang Zhao ${ }^{1,2,{ }^{*}}$, Xiangpeng Dai ${ }^{1,2,{ }^{*}}$, Wei $\mathrm{Li}^{1,2}$, Lei Liu ${ }^{1}$, Haifeng Wan ${ }^{1,2}$, Yang Yu ${ }^{1}$, Liu Wang ${ }^{1}$, Qi Zhou ${ }^{1}$

${ }^{I}$ State Key Laboratory of Reproductive Biology, Institute of Zoology, Chinese Academy of Sciences, 1st Beichen West Road, Beijing 100101, China; 'araduate School, Chinese Academy of Sciences, Beijing 100049, China

Mouse cloning from fertilized eggs can assist development of approaches for the production of "genetically tailored" human embryonic stem (ES) cell lines that are not constrained by the limitations of oocyte availability. However, to date only zygotes have been successfully used as recipients of nuclei from terminally differentiated somatic cell donors leading to ES cell lines. In fertility clinics, embryos of advanced embryonic stages are usually stored for future use, but their ability to support the derivation of ES cell lines via somatic nuclear transfer has not yet been proved. Here, we report that two-cell stage electrofused mouse embryos, arrested in mitosis, can support developmental reprogramming of nuclei from donor cells ranging from blastomeres to somatic cells. Live, full-term cloned pups from embryonic donors, as well as pluripotent ES cell lines from embryonic or somatic donors, were successfully generated from these reconstructed embryos. Advanced stage pre-implantation embryos were unable to develop normally to term after electrofusion and transfer of a somatic cell nucleus, indicating that discarded pre-implantation human embryos could be an important resource for research that minimizes the ethical concerns for human therapeutic cloning. Our approach provides an attractive and practical alternative to therapeutic cloning using donated oocytes for the generation of patient-specific human ES cell lines.

Keywords: developmental reprogramming; cleaved embryos; nuclear transfer; mitotic arrest; electrofusion; MG-132 Cell Research (2011) 21:770-778. doi:10.1038/cr.2010.180; published online 28 December 2010

\section{Introduction}

Studies conducted 50 years ago demonstrated that nuclei from differentiated cells could be successfully injected into unfertilized frog eggs resulting in cloned amphibians [1]. These studies repudiated views of pioneering nuclear transfer scientists that the differentiated state would be irreversible following nuclear transfer [2]. Initially, the field of mammalian cloning was also believed to be impossible based on repeated reprogramming failures using zygotic cytoplast [3]; and the success of reprogrammed development remained confined only to exchange of pronuclei between two one-cell embryos

*These three authors contributed equally to this work.

Correspondence: Qi Zhou

Tel: 86-10-64807299; Fax: 86-10-64807306

E-mail: qzhou@ioz.ac.cn

Received 12 July 2010; revised 7 October 2010; accepted 24 October 2010; published online 28 December 2010
[4]. However, the discovery that the cytoplasm of oocytes is adequate to support reprogramming of donor nuclei revived the field of mammalian cloning.

To avoid technical and ethical concerns, Wakayama et al. [5] tried to use zygotes as recipients for somatic cell nuclei as done by Solter [6]. This work showed zygotes are inappropriate recipients of nuclei for reprogramming. Recently Egli et al. [7] demonstrated that mouse metaphase zygotes were capable of supporting nuclear reprogramming after chromosome transfer. The authors concluded that during metaphase stage the nuclear envelope breaks down and factors present inside pronuclei spread throughout the cytoplasm, making them available to support early embryonic development of reconstructed embryos. Egli et al. [8] further showed that one blastomere from two-cell embryos could also reprogram embryonic stem (ES) nuclei to blastocyst stage, and this can produce chimeric mice with contributions from both the ES nuclei and the fertilized eggs. Whether the cytoplast of cleaved embryos, even after electrofusion, could also 
support the reprogramming of somatic cell nuclei to produce competent ES cells remained unknown.

Since the first mammal was cloned from an adult somatic cell [9], it has been expected that one day therapeutic cloning will become a useful tool to produce human ES cells derived from embryos reconstructed from donor cells of specific adult patients. These personalized stem cells were thought to be advantageous by minimizing the possibility of immune-rejection, a serious problem in transplantation medicine. The field of stem cell research and therapeutic cloning has since advanced rapidly. Successful derivation of stem cells from in vitro fertilized (IVF) human embryos has been reported [10]. However, it is still a significant challenge to obtain competent reconstructed embryos as the first step toward creating the derived stem cells for therapeutic cloning. One of the major problems continues to be the relative scarcity of biological materials for research and future medical interventions, as the supply of MII oocytes has long been the rate-limiting factor for such research. These considerations, along with the procurement of human oocytes/ embryos, raise medical, logistical and ethical questions, including most importantly the potential for commercial exploitation of women.

In this study, we report that electrofused two-cell stage embryos are capable of supporting full-term development of cloned embryos using blastomeric and ES cells as nuclear donors, but the approach failed to produce fullterm development for somatic cell donors. Nevertheless, ES cells can be successfully derived from reconstructed somatic donor embryos. To the best of our knowledge, no previous reports are available showing utilization of cleavage stage embryos for the purpose of ES cell derivation from terminally differentiated donor nuclei.
Moreover, the failure of blastomeres to support fullterm development after fusion and transfer of a somatic cell nucleus further reduces the ethical concerns related to the potential for producing a cloned human. The use of previously discarded preimplant embryos from fertility clinic repositories would provide an alternative and abundant source of biological materials capable of supporting nuclear reprogramming for potential applications in human therapeutic cloning and regenerative medicine.

\section{Results}

\section{Tetraploid embryo cell cycle synchronization}

The majority of tetraploid mouse embryos were cleaved between 48-60 h post human chorionic gonadotropin (hCG) injection. The cleavage time of the tetraploid embryos is strongly correlated with diploid embryo cleavage time (Supplementary information, Table S1). Synchronized tetraploid embryos with two distinct nuclei (obtained from blastomeres) were generated in media containing demecolcine (DC), a colchicine-related drug that depolymerizes microtubules and limits spindle formation during metaphase (Supplementary information, Table S2) [11]. This process appeared to be reversible, since the tetraploid embryos could regain mitotic activity and continue through repeated cell cycles upon release from DC exposure (Supplementary information, Table S3). The two sets of chromosomes started forming a metaphase spindle $30 \mathrm{~min}$ after DC withdrawal and were organized on the metaphase plate after 15 min. Embryo cleavage started $70 \mathrm{~min}$ after release from arrest, and we thus, determined that the optimal window for enucleation is between 40 and 70 min after DC treatment (Supplementary information, Figure S3) and consistent results

Table 1 Developmental ability of metaphase cell cycle arrested tetraploid embryos reconstructed with chromosome transfer from different donor cells

\begin{tabular}{|c|c|c|c|c|c|c|c|c|c|}
\hline Donor cells & $\begin{array}{c}\text { No. } \\
\text { manipulated }\end{array}$ & $\begin{array}{l}\text { No. cleaved } \\
\text { ( } \% \text { of } \\
\text { manipulated) }\end{array}$ & $\begin{array}{c}\text { Morula } \\
48 \mathrm{~h} \\
\text { after } \\
\text { CT }\end{array}$ & $\begin{array}{c}\text { Blastocyst } \\
48 \mathrm{~h} \\
\text { after } \\
\text { CT }\end{array}$ & $\begin{array}{c}\text { Blastocyst } \\
\text { ( } \% \text { of } \\
\text { cleaved) }\end{array}$ & $\begin{array}{l}\text { No. of } \\
\text { embryos } \\
\text { transferred } \\
\text { (recipients) }\end{array}$ & $\begin{array}{l}\text { No. of } \\
\text { pregnant } \\
\text { recipients }\end{array}$ & $\begin{array}{c}\text { Implantations } \\
19.5 \mathrm{dpc}\end{array}$ & Pups \\
\hline Tetraploid embryo * & 57 & $48(84 \%)$ & 4 & 42 & $87.5 \%$ & $42(4)$ & 3 & 23 & 0 \\
\hline Two-cell embryo & 70 & $49(70 \%)$ & 16 & 23 & $46.9 \%$ & $35(4)$ & 3 & - & 11 \\
\hline ESC & 865 & $576(67 \%)$ & 247 & 228 & $39.6 \%$ & $306(26)$ & 11 & 107 & 1 \\
\hline $\begin{array}{l}\text { Embryonic fibroblast } \\
\text { (OCT4::GFP) }\end{array}$ & 191 & $103(54 \%)$ & $39 \ddagger$ & $10 \%$ & $9.7 \%$ & - & - & - & \\
\hline $\begin{array}{l}\text { Adult fibroblast } \\
\text { (Tail tip) }\end{array}$ & 187 & $114(61 \%)$ & $82 \ddagger$ & $17 \dagger$ & $9.1 \%$ & - & - & - & \\
\hline
\end{tabular}

CT; chromosome transfer; *The genome was transferred back into the same embryo. $\$$ The number of blastocysts was scored $60 \mathrm{~h}$ after chromosome transfer. 

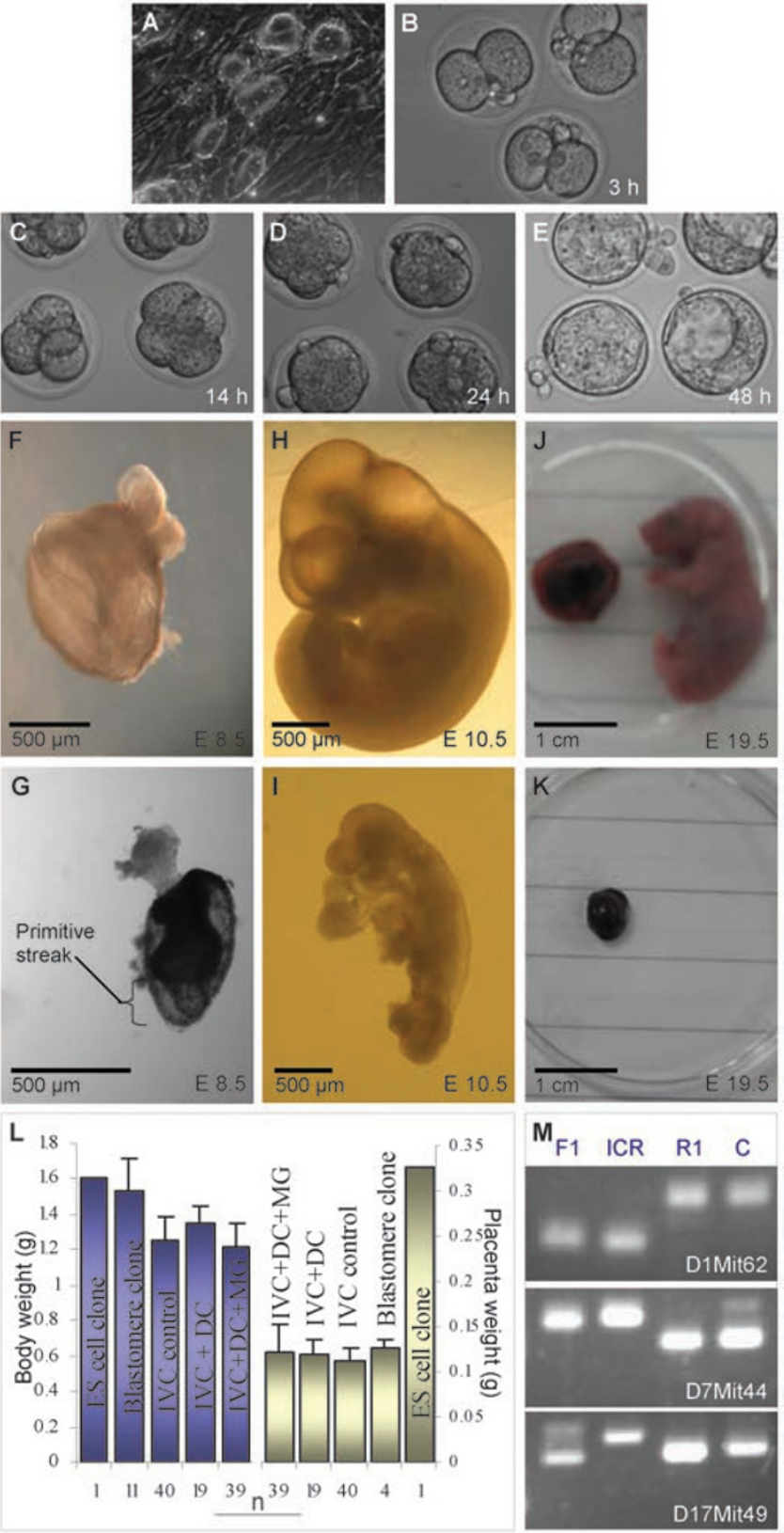

Figure 1 Nuclear reprogramming and developmental potential in vitro and in vivo after chromosome transfer from ES cells into mitotic tetraploid embryos. (A) R1 donor ES cells. (B-E) In vitro development of preimplantation embryos after tetraploid embryo chromosome transfer, from two-cell to blastocyst stages. Hours indicate time after chromosome transfer. (F-K) In vivo developmental comparisons of cloned embryos (produced by chromosome transfer) and control embryos (from tetraploid embryos). (F, G) E8.5 embryos. (F) Cloned embryo approximately at the same developmental stage as normal fertilized embryo; (G) tetraploid embryo resembles E7 but possessing much smaller primitive streak. (H, I) E10.5 embryos. (H) Cloned embryo with normal morphology; (I) best control embryo, smaller in size and abnormal in shape. (J, K) E19.5. (J) Live cloned pup with enlarged placenta; (K) placenta only. (L) Bar diagram showing weights of pups (left) and their placenta (right). (M) DNA genotyping of ES cell-cloned placenta confirms its ES cell provenance. were obtained during the enucleation and chromosome transfer process (Supplementary information, Figure S4). MG-132 was used to allow spindle polymerization, and during this period chromosome position could be visualized by differential interference contrast (DIC) (Supplementary information, Figure S2E).

To evaluate the effect of DC-induced cell cycle arrest on full-term developmental potential of mouse embryos, we temporarily arrested normally fertilized diploid embryos at the same embryonic stage as the tetraploid embryos. Fertilized zygotes, during transition from the one to two-cell embryonic stages, were synchronized at mitosis. The effect of MG-132 treatment during progression from pro-metaphase to metaphase arrest was also evaluated. We found no effect on average body and placenta weight by DC or MG-132 treatment (Figure 1L).

\section{Cytoplast of electrofused tetraploid embryos possesses full-term developmental potential}

To test whether the cytoplast of electrofused tetraploid embryos can support normal embryo development, the spindles of tetraploid embryos having a double set of chromosomes were replaced with spindles carrying a normal set of chromosomes from two-cell donor blastomeres of the same embryonic and cell cycle stages following DC and MG-132 treatment. Of the reconstructed tetraploid embryos using two-cell embryos as nuclear donors that successfully cleaved, $46.9 \%$ developed into blastocyst. 35 embryos were transferred into recipient females, and $11(31.4 \%)$ resulted in live born pups (Table $1)$. The recipient females delivered the pups normally without cesarean section.

Mitosis-arrested tetraploid embryos support nuclear reprogramming for ES donors

The experiments described so far demonstrated that the double chromosome content after blastomere fusion could be replaced successfully with a normal set of chromosomes to allow the derivation of live born mice. To test whether the tetraploid embryos enucleated in mitosis are able to reprogram donor nuclei from a different source of cells, a nuclear transfer experiment was conducted using nuclei from R1 ESC (Figure 1A) as donors. The donor cells were arrested in mitosis with demecolcine, and consequently their chromosomes were transferred into the enucleated mitotic tetraploid embryos without a spindle. After nuclear transfer and release from MG-132, the cloned embryos cleaved within $2 \mathrm{~h}$ (Figure $1 B$ ) at a rate of $67 \%$; and $39.6 \%$ of these cleaved embryos developed to the blastocyst stage (Table 1). Embryos cleaved rapidly and attained the blastocyst stage within $48 \mathrm{~h}$ after release from the cell cycle arrest (Figure 1B- 
1E).

The blastocysts, from the above ES-derived nucleartransferred embryos, as well as tetraploid control blastocysts, were transferred to pseudopregnant recipients to evaluate their developmental potential in vivo. Embryonic development was compared between ES-derived and tetraploid control embryos at E8.5, E10.5 dpc and fullterm development at E19.5 dpc. 4 out of $7(57.1 \%)$ and 3 out of $10(30.0 \%)$ ES cell-derived embryos developed normally at E8.5 and E10.5 dpc, respectively (Figure 1F and $1 \mathrm{H})$. Among control tetraploid blastocysts, 12 out of $35(34.3 \%)$ and 3 out of $130(2.3 \%)$ developed at E8.5 and E10.5 dpc, respectively (Figure $1 \mathrm{G}$ and 1I). Delayed developmental stages and smaller primitive streaks were noted with the control tetraploid embryos.

One live pup was recovered out of 306 ES-derived embryos at E19.5 after cesarean section (Table 1 and Figure $1 \mathrm{~J})$. The neonatal weight of the live pup was in the normal range $(1.601 \mathrm{~g})$, while the weight of the placenta was approximately three times higher $(0.327 \mathrm{~g})$, similar to what was observed in previous studies of cloned mice [12] (Figure 1L). In contrast, neither pups nor degenerating embryos, but only placentas, were recovered from the tetraploid control as expected (Figure 1K). The R1 provenance of the cloned pup was verified by PCR analysis for polymorphic markers from genomic DNA extracted from the placenta of the ES cell-derived cloned pup (Figure $1 \mathrm{M})$.

Mitosis-arrested tetraploid embryos support nuclear reprogramming from somatic donors

We next determined whether, and to what extent, the mitosis-arrested tetraploid embryo can support nuclear reprogramming from a somatic cell donor. For this, we used mouse embryonic fibroblasts modified to express a green fluorescent protein (GFP) transgene under the control of Oct4 (Oct4::GFP) [13]. Oct4 plays an important role in the establishment and maintenance of the mammalian totipotent cell population [14] and its expression is detected in early embryos, as well as pluripotent ES cells, but not in somatic tissues [15]. Therefore, the reactivation of Oct4 as reported by GFP expression can be used as a reflection of successful reprogramming [16].

Our results showed that in spite of the shorter duration of donor nuclei exposure to cytoplast of tetraploid embryos, the Oct4::GFP transgene was reprogrammed properly and faithfully reproduced the endogenous expression pattern of Oct4 in embryos. As shown in Figure 2, GFP expression was absent in somatic nuclear donor and twocell embryos, but became much stronger with advancing embryonic stage; and fluorescence was clearly visible in late cleavage stage embryos (Figure 2D-2H) similar to normal fertilized embryos [17]

Chromosome-transferred embryos give rise to ES cell lines

Out of 14 blastocysts cloned from R1 ES cells, we derived eight CTES (chromosome transferred ES) cell lines (ES-Tetra 1-8). The efficiency of cell line production was somewhat higher than with ICSI embryos $(57.1 \%$ vs $40.7 \%$, respectively; Table 2). However, for fibroblastcloned blastocysts the success rate is low and only one cell line (F-Tetra 1) was derived. Four of these CTES cell lines (three ES-derived (ES-Tetra 5-7) and one fibroblastderived (F-Tetra 1)), were further evaluated and demonstrated the same pluripotency as typical ES cells, including expression of pluripotent ES markers, such as Oct4, Nanog and SSEA1 (Figure 3D-3F). Normal karyotype was observed (Figure 3G). PCR analysis of polymorphic markers confirmed the genetic origin of the ES cell lines by comparing cell line genomic DNA to that of the donor cells (Figure $3 \mathrm{H}$ ). In vivo differentiation potential of these ES cell lines was also confirmed using a teratoma assay by injecting cells from these stem cell lines into the flanks of SCID mice. Histological examination of the resulting teratomas demonstrated differentiated cell types representative of all three germ layers (Figure 3J-3L).

The fibroblast-derived CTES cells (F-Tetra 1) could contribute to chimera formation after injection into diploid blastocysts (Figure 3I). To further investigate the level of pluripotency of the fibroblast-derived CTES cell line (F-Tetra 1), we first evaluated the in vitro activation of the Dlk1-Dio3 region. The activation of this imprinted region positively correlates with pluripotency of ES cells [18]. Expression differences for this region were evaluated by quantitative PCR analysis of F-Tetra 1 cells, which revealed a pattern similar to that of an ES cell line that is tetraploid blastocyst complementation competent (Figure 4). The developmental pluripotency of F-Tetra 1 was further confirmed by in vivo evaluation. The production of late gestation chimeric embryos (E14.5), after $4 \mathrm{n}$ blastocyst complementation, and normal gonad development (Figure 3M-3O) proved germ line competence of the fibroblast-derived CTES cells [19].

\section{Discussion}

Using cleavage stage fused embryos as nuclear transfer recipients, we produced live-born cloned mice from blastomeres and ES cells, in addition to generating pluripotent ES cell lines. We observed that electrofused tetraploid embryos, after chromosome transplantation, possessed different degrees of developmental potential when nuclei from blastomeres, ES cells or somatic cells were 

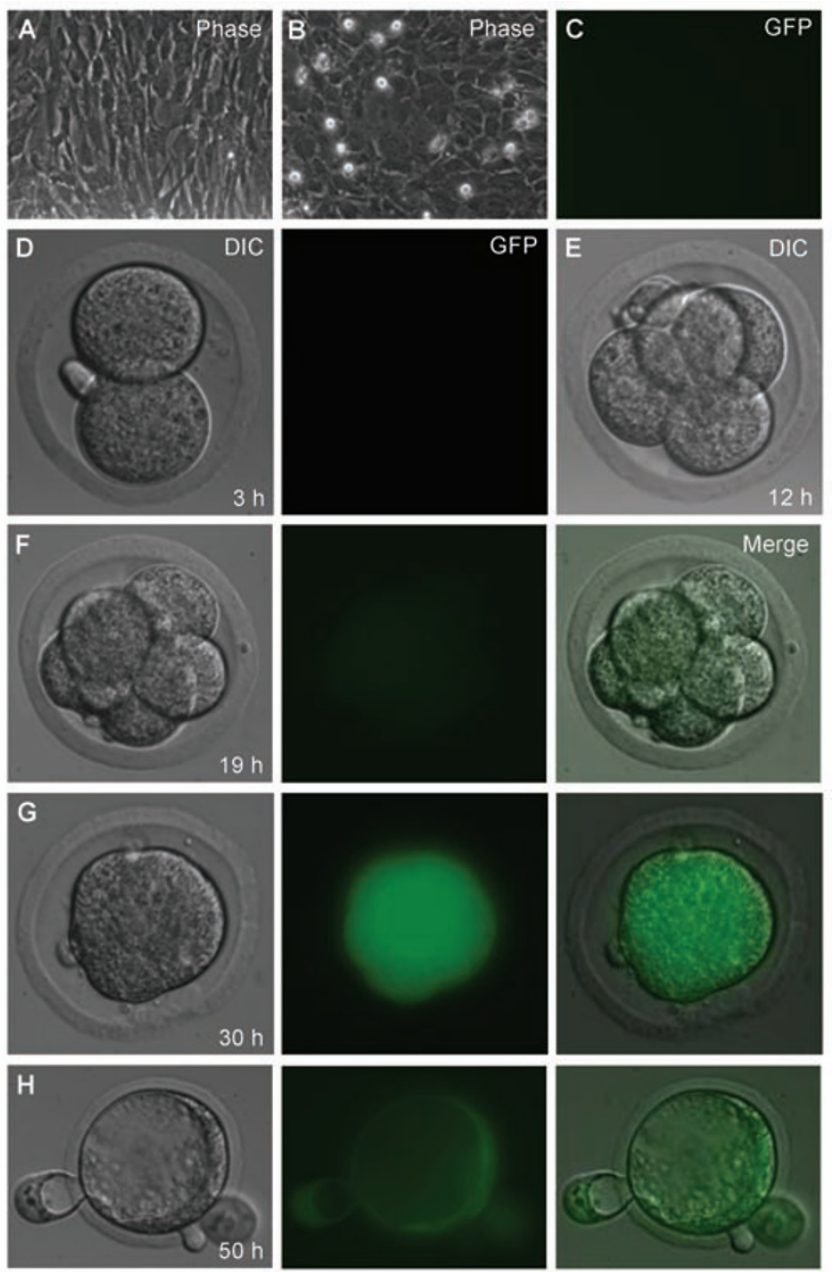

Figure 2 Oct4 expression pattern after somatic cell chromosome transfer into metaphase tetraploid embryos. (A, B) Fibroblasts cultured from an E 13.5 mouse embryo carrying an Oct4::GFP transgene (A) and arrested in mitosis by demecolcine (B). (C) Complete absence of transgene in the cells represents somatic cells. (D, E) Two-cell stage and four-cell stage embryos after somatic cell chromosome transfer. (F) Sixcell stage somatic cell transfer embryo, Oct4::GFP first became detectable. (G, H) Morula and blastocyst stage embryos after somatic cell chromosome transfer with strong expression of the GFP transgene. Hours indicated the time after chromosome transfer. used as donors. The fused tetraploid embryo itself lacked full-term developmental potential; this is consistent with previous findings that transplanting a somatic genome into intact cleavage stage embryonic blastomeres fails to support any post-implantation development [20]. These failures most likely are due to the tetraploid nature of the reconstructed embryos [21]. The full-term developmental potential of blastomeres has been demonstrated in mouse [22-24] or rat [25]; however, whether the electrofusion of blastomeres affects the full-term development is still not clear. Here, we have shown that if the polyploidy of these embryos is rectified, full-term development can be recovered, even though the transcripts present in the cytoplast of blastomeres are different from zygotes [26].

For many years, unfertilized oocytes were considered to be the only source of nuclear transfer recipients to support developmental reprogramming of donor nuclei. Recent studies, in which pronuclei were punctured before enucleation [27] or when enucleation was done before pronuclei formation [28], have proved that zygotes can also be successfully used as nuclear transfer recipients. In addition, Egli et al. [7] showed that mouse zygotes temporarily arrested in mitosis could fully support somatic cell reprogramming. Recently Egli et al. [8] implicated that blastomeres from two-cell embryos could reprogram ES cell nuclei. This technique could be used to generate chimeric (fertilized plus NT cloned) animals after transplantation. Our results show that electrofused embryos in metaphase stage could support reprogramming of blastomeres and ES cells and full-term development of the resulting cloned embryos. Thus, early cleavage stage embryos can potentially be used as recipients for nuclear transfer to support nuclear reprogramming, but the interesting question will be how efficient this process is and the extent of this reprogramming as we go further into the cleavage stage of the preimplantation embryos. The identification of the critical factors that support developmental reprogramming of reconstructed embryos is also a priority.

The cell cycle stage of the nuclear transfer recipients, especially with electrofused tetraploid embryos where

Table 2 Derivation of ES cell lines from ES cell and fibroblast-derived blastocysts

\begin{tabular}{llccc}
\hline Recipient cytoplasm & Origin of ES cells & No. of blastocysts & $\begin{array}{c}\text { No. of outgrowths } \\
(\%)\end{array}$ & $\begin{array}{c}\text { No. of ES cell lines } \\
(\% \text { of blastocyst / \% of outgrowth) }\end{array}$ \\
\hline Tetraploid embryo & ES cell derived & 14 & $9(64.3 \%)$ & $8(57.1 \% / 88.9 \%)$ \\
& Fibroblast derived & 10 & $6(60.0 \%)$ & $1(10.0 \% / 16.7 \%)$ \\
MII stage oocyte & Fibroblast derived & 29 & $10(34.5 \%)$ & $8(27.6 \% / 80.0 \%)$ \\
& Sperm cell derived & 27 & $14(51.9 \%)$ & $11(40.7 \% / 78.6 \%)$ \\
\hline
\end{tabular}


the nuclei from different cells may be at different stages, is very critical for the success of nuclear transfer experiments. To synchronize the fused tetraploid embryos into metaphase, we used the microtubule-destabilizing agent DC, which was previously used for induced enucleation in nuclear transfer experiments [11, 29-30]. Regardless of the polyploidizing nature of DC [31], no reports regarding its effects on full-term embryo development were available.

When the embryos were further exposed to the spindle-polymerizing agent MG-132 for progression through prometaphase to metaphase, their in vitro development was improved. Similarly, a positive effect of the protease
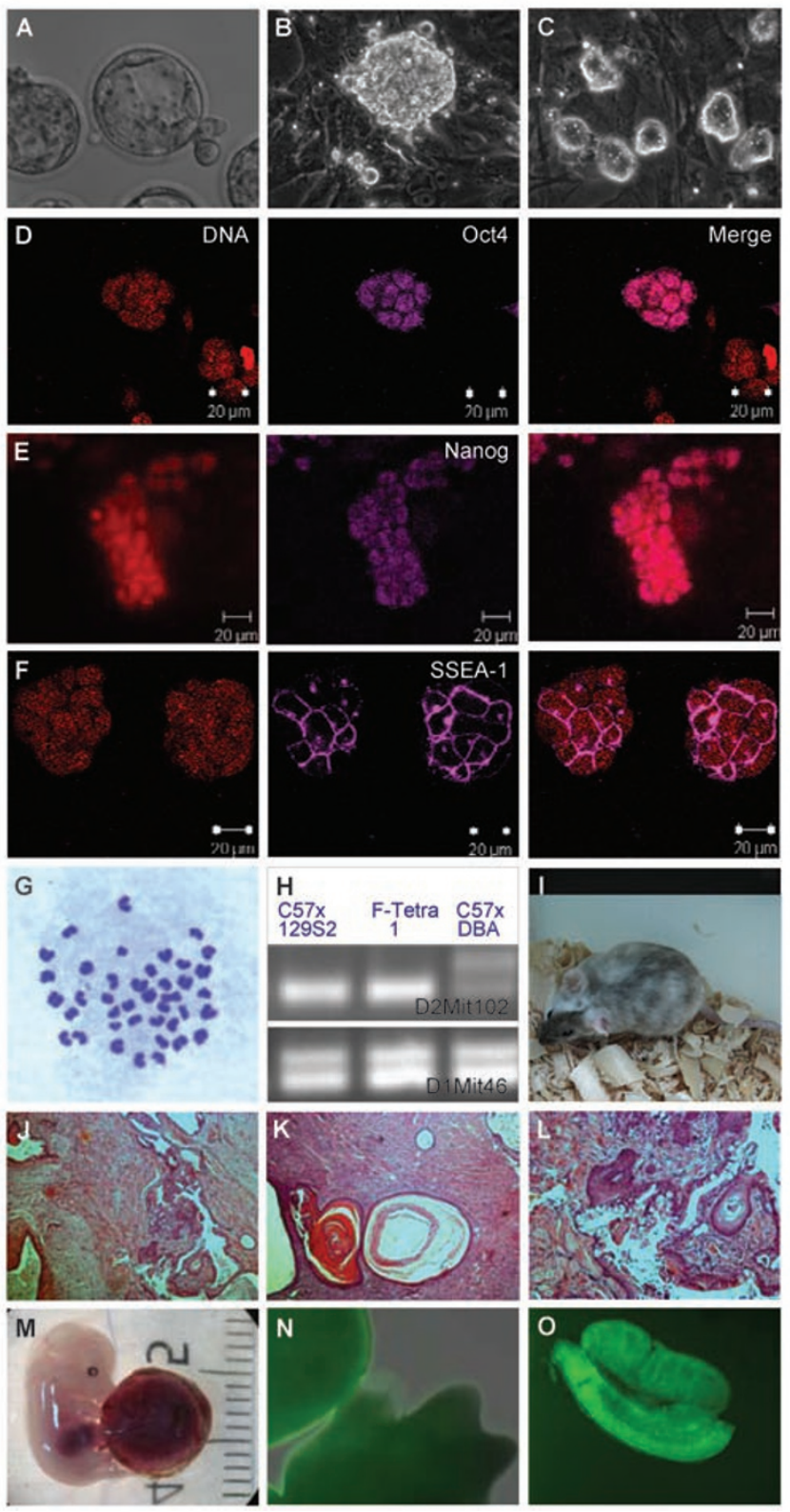

inhibitor MG-132 was reported in nuclear transfer experiments by overcoming the negative effects of sub-optimal procedures [32]. Alternatively, the developmental improvement may be due to the inhibition of maturation promotion factor inactivation, which is mediated through a proteasome-mediated cyclin degradation pathway [33].

The integrity of recipient cells is very important for the developmental reprogramming of the reconstructed embryos. Cleavage stage electrofused human embryos that may be available for such research are more likely to have higher quality. First, in IVF programs, to avoid adverse outcomes from twin pregnancies, only embryos with the highest implantation and developmental potential are selected for transfer. Assessment of zygotes by pronuclear score [34-35], the time of cleavage to the two-cell stage [36], and morphology of cleaved zygotes [37] are reliable indicators for the selection of embryos with the highest capability of implantation and successful pregnancy after transfer. Second, because time of fertilization is usually unavailable, the metaphase stage of frozen-thawed zygotes is difficult to estimate and prolonged exposure to cell cycle arrest treatment or repeated observations are required. Our results demonstrated that the metaphase stage of electrofused embryos is dependent on their first cleavage time, and cell cycle synchronization can be attained in minimal exposure to unnatural agents.

We established many ES cell lines after nuclear transfer into electrofused embryos. For ES cell donors, a satisfactory ES cell derivation rate is obtained. Four ES lines were evaluated for typical stem cell characteristics. These ES cell lines can be valuable resources for the

Figure 3 Derivation of ES cell line from chromosome transferred tetraploid embryos. (A) Diploid set of chromosome transferred into enucleated electrofused tetraploid embryos and cultured in vitro to blastocyst stage. (B) Outgrowth from inner cell mass of the blastocyst 5 days after plating. (C) Tetraploid embryo chromosome transferred (TetraCT) ES cell line culture. (D-F) Expression of pluripotent marker gene Oct4 (D), nanog (E) and the embryonic antigene SSEA-1 (F). (G) Mitotic chromosomal spread of a TetraCT ES cell line with a normal set of 40 chromosomes. (H) DNA genotyping confirming somatic donor cell (C57 × 129S2) provenance. (I) A male chimera after injection of TetraCT ES cells (F-Tetra 1) into diploid blastocysts. (J-L) Hematoxylin and eosin staining of teratoma sections showed differentiation of TetraCT ES cells to various tissues. Brain tissue (ectoderm derivative) (J), Cartilage and muscle (mesoderm derivative) (K) and gut (endoderm derivative) (L). (M-O) Development of GFP labeled TetraCT ES cells (F-Tetra 1), after tetraploid blastocyst complementation. E $14.5 \mathrm{dpc}$, live fetus by tetraploid complementation (M), with strong expression of GFP (N), having normal gonad development (O). 


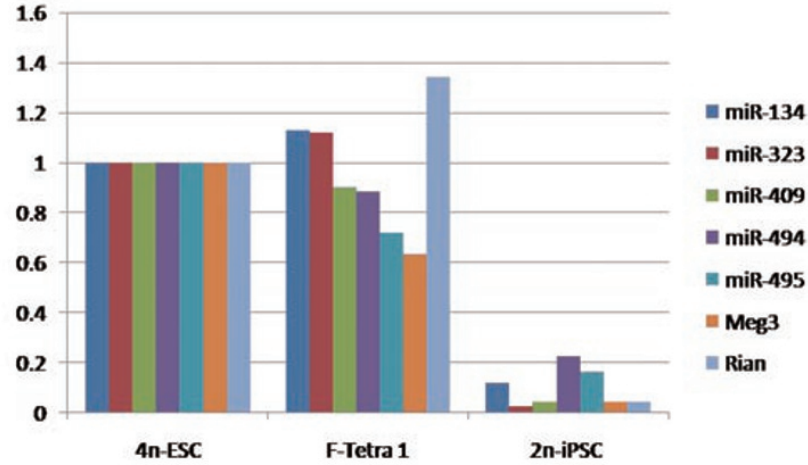

Figure 4 In vitro pluripotency evaluation by DIk1-Dio3 region. Expression comparison of the DIk1-Dio3 region among tetraploid complementation competent ES cells, fibroblast-derived Tetra CTES cells and iPS cell lines that were only able to produce diploid chimeric mice (2n-iPS cells).

study of underlying molecular mechanisms governing nuclear reprogramming. Our results suggest an alternative approach for generating "patient-specific" ES cell lines. This could be particularly valuable not only because it presents an unexplored resource to produce specific human ES cells, which previously solely relied on the availability of limited donated oocytes, but also because of its feasibility. A study [38] showed that $73 \%$ of the US infertile couples are in favor of the use of their spare embryos for stem cell research. There were around 400000 leftover embryos in storage in the US fertility clinics through 2002. Utilizing cleavage stage preimplantation embryos to generate cloned animals or therapeutic human ESC lines will provide additional advantages with tremendous potential for future therapeutic intervention. In addition, the inability of electrofused advanced stage preimplantation embryos to develop to full term provides a possible means to diminish the logistical and ethical controversies that are attached with ES cell research.

\section{Materials and Methods}

\section{Experimental design}

We evaluated the reprogramming and developmental ability of two-cell stage, cleaved embryos after electrofusion. The details of our experimental design are described in Supplementary information, Figure S1.

\section{Embryo production, culture and electrofusion}

B6D2F1 $(\mathrm{C} 57 \mathrm{BL} / 6 \times \mathrm{DBA} / 2)$ mice (8 to 10 weeks old) were used as embryo donors. All mice were housed on a $12 \mathrm{~h}$ of dark and light cycles and were cared for on the basis of animal protocols approved by the Institutional Animal Care Committee. The female mice were super-ovulated by intraperitoneal injection of equine chorionic gonadotropin (eCG 7.5 IU, Ningbo Sansheng
Pharmaceutical, China) followed by injection of hCG (7.5 IU, Ningbo Sansheng Pharmaceutical) $48 \mathrm{~h}$ later. After hCG administration, females were mated individually with B6D2F1 males with proven fertility. Zygotes or two-cell embryos were flushed from the oviducts of plugged females, 30-32 $\mathrm{h}$ after hCG injection. Modified Hepes-buffered HCZB medium [39] was used for embryo operations at room temperature unless otherwise stated. If needed, zygotes or two-cell embryos were exposed briefly at room temperature to HCZB with $0.1 \%$ bovine testicular hyaluronidase to remove any remaining cumulus cells. After several washings with $\mathrm{HCZB}$, the embryos were transferred to culture medium.

Embryos were cultured in groups of 20-30 in $30 \mu 1$ drops of medium KSOM (Chemicon) supplemented with amino acids in 35 $\mathrm{mm}$ standard Petri dishes (Falcon). Culture drops were overlaid with mineral oil (Sigma) and incubated in $5 \% \mathrm{CO}_{2}$ at $37{ }^{\circ} \mathrm{C}$. The two-cell embryos were selectively grouped $33 \mathrm{~h}$ and $38 \mathrm{~h}$ post hCG injection.

Between $38 \mathrm{~h}$ and $40 \mathrm{~h}$ post $\mathrm{hCG}$ injection, the blastomeres of a two-cell embryo were electrofused to produce a one-cell tetraploid embryo. A group of 20-30 two-cell embryos was transferred from KSOM medium to a drop of electrofusion medium $(0.3 \mathrm{M}$ mannitol, $0.1 \mathrm{mM} \mathrm{MgSO} 4,0.01 \%$ polyvinyl alcohol and $0.3 \%$ bovine serum albumin) and allowed to settle down. Then the embryos were aligned between the electrodes of a 0.2-mm Eppendorf Multiporator fusion chamber, filled with electrofusion medium. Prealignment of blastomeres was attained by a $3 \mathrm{~V}$ pulse for $10 \mathrm{sec}$. Fusion of the two blastomeres was induced by a single electrical pulse of $70 \mathrm{~V}$ for $35 \mu \mathrm{s}$. After several washes with HCZB medium, embryos were returned to KSOM medium at $37^{\circ} \mathrm{C}$. Embryos that had not undergone membrane fusion within $1 \mathrm{~h}$ were discarded.

\section{Cell culture and synchronization}

The R1 ES lines cells and adult tail fibroblast, collected from C57BL6/SV129 mice were used as the donor cells, respectively [40]. The R1 ES cells were routinely cultured onto mitomycininactivated mouse embryonic fibroblasts in ES cell culture medium (Dulbecco Modified Eagle Medium, high glucose (Gibco, Invitrogen), supplemented with $1000 \mathrm{U}$ LIF (leukemia inhibitory factor; Chemicon), $15 \%$ heat-inactivated fetal calf serum (Gibco), $2 \mathrm{mM}$ glutamine (Sigma), $1 \mathrm{mM}$ sodium pyruvate (Sigma), 0.1 $\mathrm{mM} \beta$-mercaptoethanol (Sigma) and $0.1 \mathrm{mM}$ nonessential amino acid (NEAA; Gibco) in the presence of penicillin and streptomycin). Mouse embryonic fibroblasts carrying a GFP transgene under the control of the Oct3/4 promoter were prepared from $13.5 \mathrm{dpc}$ fetuses as described previously [41]. Fibroblasts from mouse tail tips were cultured as described previously [42].

All the cells were synchronized in metaphase by culturing them with $0.04 \mu \mathrm{g} / \mathrm{ml}$ DC (Sigma). After $3 \mathrm{~h}$ incubation of ES cells and $5 \mathrm{~h}$ incubation of somatic cells with DC, the mitotic cells appeared loosely attached and were collected by shaking the culture dishes, and then used for nuclear transfer.

\section{Mitotic arrest of tetraploid embryos}

To synchronize tetraploid embryos in prometaphase, embryos were transferred into KSOM containing $0.05 \mu \mathrm{g} / \mathrm{ml}$ DC (Sigma), in two groups. One group of tetraploid embryos that cleaved within $33 \mathrm{~h}$ post hCG were transferred into DC between 49 to 56 $\mathrm{h}$ post hCG injection and a second group of embryos that cleaved during $>33$ to $38 \mathrm{~h}$ post hCG injection were transferred into DC 
from 52 to $58 \mathrm{~h}$ post hCG injection. For progression through prometaphase to metaphase and spindle assembly a group of 10 to 15 embryos arrested in prometaphase were washed through 1-3 drops of KSOM to remove residual DC and then transferred into CZB containing 2.5-3 $\mu \mathrm{M}$ MG-132 (Z-Leu-Leu-Leu-al; Sigma) for 30$40 \mathrm{~min}$.

\section{Chromosome and nuclear transfers}

All manipulations were performed at room temperature under DIC optics (Leica DM IRB). The micromanipulator was equipped with a piezo unit (PrimeTech, Japan) for zona drilling and for breaking plasma membranes. Metaphase-arrested tetraploid embryos were transferred for manipulation into a chamber containing oil-covered HCZB supplemented with $5 \mu \mathrm{g} / \mathrm{ml}$ cytochalasin B (CB) and $2 \mu \mathrm{M}$ MG-132 on the micromanipulator stage. After adjusting the position of each embryo the entire spindle was aspirated into the pipette within a minimal volume of cytoplasm. Mitotic donor cells were selected under DIC optics and injection pipettes with inner diameter $10 \mu \mathrm{m}$ for ES cells and 12-13 $\mu \mathrm{m}$ for fibroblasts, blastomeres were used to transfer the donor cell chromosomes. Spindle chromosome complex removal from the recipient embryo and nuclear transfer of donor nuclei was done in one step using the hole removal method [43]. The entire manipulation process was completed within a 5-30 min window after transfer of embryos into the chamber.

\section{Embryo transfer and ES cell derivation}

Cloned and control blastocyst stage embryos were transferred into the uterine horns of E2.5 pseudopregnant ICR females that had been mated with vasectomized ICR males with proven sterility. Animals were euthanized at day E8, E10 or E19.

For derivation of ES cells, we used the protocol described by Bryja [44] with slight modifications. The zonae pellucidae of cloned blastocysts were removed by treatment with $0.5 \%$ pronase (Sigma) in HCZB at $37^{\circ} \mathrm{C}$ for 3-5 min. Zona-free blastocysts were washed in $\mathrm{HCZB}$ and plated on a feeder layer of mitomycin-C inactivated confluent mouse embryonic fibroblast in a 4-well plate (Nunc). Culture of feeder cells and embryos (outgrowths) was in DMEM/F12 (1:1; Gibco), supplemented with 20\% knockout serum (Gibco), 1000 U LIF (Chemicon), 2 mM glutamine (Sigma), $1 \mathrm{mM}$ sodium pyruvate (Sigma), $0.1 \mathrm{mM} \beta$-mercaptoethanol (Sigma) and $0.1 \mathrm{mM}$ NEAA (Gibco) in the presence of penicillin and streptomycin. Outgrowth formation was defined by the spreading of trophoblast cells from the attached blastocyst. Proliferating outgrowths were dissociated using trypsin treatment and then replated on MEF until stable cell lines grew out.

\section{PCR analysis of genomic DNA}

Polymerase chain reaction (PCR) amplification of the microsatellite markers D1Mit46, D1Mit62, D2Mit102, D7Mit44 and D17Mit49 was performed as described [45]. Sequences for the primer pairs were found on the Mouse Genome Informatics web site (http://www.informatics.jax.org/searches/probe form.shtml). DNA was extracted from tail tips for control strains B6D2F1 and ICR, R1 ES cells and the associated placentae of the R1 ES cell derived cloned offspring for cloned pup and from tail tips of D6D2F1 and C57 129S2 and from Tetra1-3 ES cells for somatic cells derived ES cells. Reactions were subjected to 35 cycles of $30 \mathrm{sec}$ at $94{ }^{\circ} \mathrm{C}, 30 \mathrm{sec}$ at $55^{\circ} \mathrm{C}$, and $30 \mathrm{sec}$ at $72{ }^{\circ} \mathrm{C}$, and products were separated on a 3\% agarose gel and visualized.

\section{Terratoma formation and chimeric mice production}

The ES cells derived after nuclear transfer into tetraploid embryos were harvested by trypsinization and injected into the flanks of SCID mice. Mice were euthanized 4 weeks later and teratomas were isolated and processed for histological analysis. For chimeric mouse production both diploid and tetraploid blastocyst complementation was done. 10-15 ES cells, derived from nuclear transfer into tetraploid embryos, were injected into ICR $\times$ ICR host blastocysts with a beveled pipette. Embryos were allowed to recover for 60-90 min in $\mathrm{KSOM}$ at $37^{\circ} \mathrm{C}$ and then transferred into the uterine horns of E2.5 pseudopregnant ICR females.

\section{Expression analysis of Dlk1-Dio3 region}

The expression level of fibroblast-derived CTES cell line was compared with $4 \mathrm{n}$ competent ES cell line and iPS cell lines that were only able to produce diploid chimeric mice (2n-iPS cells), for Dlk1-Dio3 cluster region as illustrated by Liu et al. [18].

\section{Acknowledgments}

This study was supported, in part, by grants from the National High Technology R\&D Program of China (2006AA02A101), and the China National Basic Research Program (2006CB701501). We thank Eppendorf and Leica for supporting of the facility.

\section{References}

1 Gurdon JB, Elsdale TR, Fischberg M. Sexually mature individuals of Xenopus laevis from the transplantation of single somatic nuclei. Nature 1958; 182:64-65.

2 Briggs R, King TJ. Transplantation of living nuclei from blastula cells into enucleated frogs' eggs. Proc Natl Acad Sci USA 1952; 38:455-463.

3 McGrath J, Solter D. Nuclear transplantation in the mouse embryo by microsurgery and cell fusion. Science 1983; 220:1300-1302.

4 McGrath J, Solter D. Inability of mouse blastomere nuclei transferred to enucleated zygotes to support development in vitro. Science 1984; 226:1317-1319.

5 Wakayama T, Tateno H, Mombaerts P, Yanagimachi R. Nuclear transfer into mouse zygotes. Nat Genet 2000; 24:108109.

6 Solter D. Cloning claims challenged. Nature 1999; 399:13.

7 Egli D, Rosains J, Birkhoff G, Eggan K. Developmental reprogramming after chromosome transfer into mitotic mouse zygotes. Nature 2007; 447:679-685.

8 Egli D, Sandler VM, Shinohara ML, Cantor H, Eggan K. Reprogramming after chromosome transfer into mouse blastomeres. Curr Biol 2009; 19:1403-1409.

9 Wilmut I, Schnieke AE, McWhir J, Kind AJ, Campbell KH. Viable offspring derived from fetal and adult mammalian cells. Nature 1997; 385:810-813.

10 Adewumi O, Aflatoonian B, Ahrlund-Richter L, et al. Characterization of human embryonic stem cell lines by the International Stem Cell Initiative. Nat Biotechnol 2007; 25:803-816. 
11 Gasparrini B, Gao S, Ainslie A, et al. Cloned mice derived from embryonic stem cell karyoplasts and activated cytoplasts prepared by induced enucleation. Biol Reprod 2003; 68:12591266.

12 Wakayama T, Rodriguez I, Perry AC, Yanagimachi R, Mombaerts P. Mice cloned from embryonic stem cells. Proc Natl Acad Sci USA 1999; 96:14984-14989.

13 Yoshimizu T, Sugiyama N, De Felice M, et al. Germlinespecific expression of the Oct-4/green fluorescent protein (GFP) transgene in mice. Dev Growth Differ 1999; 41:675684.

14 Nichols J, Zevnik B, Anastassiadis K, et al. Formation of pluripotent stem cells in the mammalian embryo depends on the POU transcription factor Oct4. Cell 1998; 95:379-391.

15 Schöler HR, Dressler GR, Balling R, Rohdewohld H, Gruss P. Oct-4: a germline-specific transcription factor mapping to the mouse t-complex. EMBO J 1990; 9:2185-2195.

16 Boiani M, Gentile L, Gambles VV, Cavaleri F, Redi CA, Schöler HR. Variable reprogramming of the pluripotent stem cell marker Oct4 in mouse clones: distinct developmental potentials in different culture environments. Stem Cells 2005; 23:1089-1104.

17 Palmieri SL, Peter W, Hess H, Schöler HR. Oct-4 transcription factor is differentially expressed in the mouse embryo during establishment of the first two extraembryonic cell lineages involved in implantation. Dev Biol 1994; 166:259-267.

18 Liu L, Luo GZ, Yang W, et al. Activation of the imprinted Dlk1-Dio3 region correlates with pluripotency levels of mouse stem cells. J Biol Chem 2010; 285:19483-19490.

19 Wernig M, Meissner A, Foreman R, et al. In vitro reprogramming of fibroblasts into a pluripotent ES-cell-like state. $\mathrm{Na}$ ture 2007; 448:318-324.

20 Eckardt S, Leu NA, Kurosaka S, McLaughlin KJ. Differential reprogramming of somatic cell nuclei after transfer into mouse cleavage stage blastomeres. Reproduction 2005; 129:547-556.

21 Kaufman MH, Webb S. Postimplantation development of tetraploid mouse embryos produced by electrofusion. Development 1990; 110:1121-1132.

22 Tsunoda Y, Yasui T, Shioda Y, Nakamura K, Uchida T, Sugie T. Full-term development of mouse blastomere nuclei transplanted into enucleated two-cell embryos. J Exp Zool 1987; 242:147-151.

23 Kono T, Tsunoda Y. Development of single blastomeres from four- and eight-cell mouse embryos fused into the enucleated half of a two-cell embryo. Gamete Res 1989; 22:427-434.

24 Kono T, Tsunoda Y, Nakahara T. Production of identical twin and triplet mice by nuclear transplantation. J Exp Zool 1991; 257:214-219.

25 Roh S, Guo J, Malakooti N, Morrison JR, Trounson AO, Du ZT. Birth of rats following nuclear exchange at the 2-cell stage. Zygote 2003; 11:317-321.

26 Zeng F, Schultz RM. RNA transcript profiling during zygotic gene activation in the preimplantation mouse embryo. Dev Biol 2005; 283:40-57.

27 Greda P, Karasiewicz J, Modlinski JA. Mouse zygotes as recipients in embryo cloning. Reproduction 2006; 132:741-748.

28 Schurmann A, Wells DN, Oback B. Early zygotes are suitable recipients for bovine somatic nuclear transfer and result in cloned offspring. Reproduction 2006; 132:839-848.
29 Lan GC, Wu YG, Han D, et al. Demecolcine-assisted enucleation of goat oocytes: protocol optimization, mechanism investigation, and application to improve the developmental potential of cloned embryos. Cloning Stem Cells 2008; 10:189202.

30 Tani T, Shimada H, Kato Y, Tsunoda Y. Demecolcine-assisted enucleation for bovine cloning. Cloning Stem Cells 2006; 8:61-66.

31 Fujikawa-Yamamoto K, Miyagoshi M, Yamagishi H. Establishment of a tetraploid cell line from mouse H-1 (ES) cells highly polyploidized with demecolcine. Cell Prolif 2007; 40:327-337.

32 Gao S, Han Z, Kihara M, Adashi E, Latham KE. Protease inhibitor MG132 in cloning: no end to the nightmare. Trends Biotechnol 2005; 23:66-68.

33 Josefsberg LB, Galiani D, Dantes A, Amsterdam A, Dekel $\mathrm{N}$. The proteasome is involved in the first metaphase-to-anaphase transition of meiosis in rat oocytes. Biol Reprod 2000; 62:1270-1277.

34 Scott L. Pronuclear scoring as a predictor of embryo development. Reprod Biomed Online 2003; 6:201-214.

35 Senn A, Urner F, Chanson A, Primi MP, Wirthner D, Germond M. Morphological scoring of human pronuclear zygotes for prediction of pregnancy outcome. Hum Reprod 2006; 21:234239.

36 Shoukir Y, Campana A, Farley T, Sakkas D. Early cleavage of in-vitro fertilized human embryos to the 2-cell stage: a novel indicator of embryo quality and viability. Hum Reprod 1997; 12:1531-1536.

37 Hesters L, Prisant N, Fanchin R, et al. Impact of early cleaved zygote morphology on embryo development and in vitro fertilization-embryo transfer outcome: a prospective study. Fertil Steril 2008; 89:1677-1684.

38 Jain T, Missmer SA. Support for embryonic stem cell research among infertility patients. Fertil Steril 2008; 90:506-512.

39 Chatot CL, Lewis JL, Torres I, Ziomek CA. Development of 1-cell embryos from different strains of mice in CZB medium. Biol Reprod 1990; 42:432-440.

40 Nagy A, Rossant J, Nagy R, Abramow-Newerly W, Roder JC. Derivation of completely cell culture-derived mice from early-passage embryonic stem cells. Proc Natl Acad Sci USA 1993; 90:8424-8428.

41 Ono Y, Shimozawa N, Ito M, Kono T. Cloned mice from fetal fibroblast cells arrested at metaphase by a serial nuclear transfer. Biol Reprod 2001; 64:44-50.

42 Wakayama T, Yanagimachi R. Cloning of male mice from adult tail-tip cells. Nat Genet 1999; 22:127-128.

43 Zhou Q, Jouneau A, Brochard V, Adenot P, Renard JP. Developmental potential of mouse embryos reconstructed from metaphase embryonic stem cell nuclei. Biol Reprod 2001; 65:412-419.

44 Bryja V, Bonilla S, Cajanek L, et al. An efficient method for the derivation of mouse embryonic stem cells. Stem Cells 2006; 24:844-849.

45 Zhao XY, Li W, Lv Z, et al. iPS cells produce viable mice through tetraploid complementation. Nature 2009; 461: 8690 .

(Supplementary information is linked to the online version of the paper on the Cell Research website.) 